\title{
ANALISA TARIF ANGKUTAN BARANG RUTE KOTA BANJARMASIN- AMUNTAI DENGAN METODE BIAYA OPERASI KENDARAAN
}

\author{
Abdurrahman ${ }^{(1)}$ Susiladewi ${ }^{(2)}$ \\ ${ }^{(1)}$ Dosen Teknik Sipil Uniska MAB \\ ${ }^{(2)}$ Dosen Fekon Uniska MAB \\ Jl. Adhyaksa No.2 Banjarmasin 70123 \\ E-mail: abdurrahman6564@gmail.com/HP.+6282149704769 \\ E-mail: dewirahmanutama@yahoo.com
}

\begin{abstract}
ABSTRAK
Seiring dengan kebutuhan dan perkembangan ekonomi yang semakin meningkat, kebutuhan akan angkutan barang juga meningkat dengan konsekuensi logis yang akan terjadi pada angkutan barang yaitu meningkatnya nilai tambah harga suatu barang. Mengingat nilai finansial yang akan terjadi dalam pergerakan transportasi barang maka penentuan tarif angkutan barang sangat dominan sebagai faktor utama yang harus dipertimbangkan karena kebijakan tarif mempunyai dampak luas dalam aplikasi angkutan barang. Tarif adalah tingkat harga atau biaya yang dibayarkan oleh pengguna jasa angkutan barang per satuan trip, berat atau per satuan volume per kilometer. Karena tarif dimaksudkan untuk mendorong terciptanya penggunaan prasarana dan sarana perangkutan secara optimum dengan mempertimbangkan lintas yang bersangkutan. Dalam perhitungan biaya (tarif angkutan) barang menggunakan pendekatan. Biaya produksi kendaraan artinya tarif angkutan barang tersebut ditetapkan berdasarkan biaya operasional kendaraan ditambah dengan sejumlah presentase pengelolaan dan keuntungan yang diperkenankan studi kasus ini meninjau tarif angkutan barang khusus rute Banjarmasin-Amuntai sepanjang \pm $200 \mathrm{~km}$ dengan angkutan darat. Dimana dalam kasus ini akibat tarif yang rendah menyebabkan kecenderungan pemilik jasa transportasi menambah jumlah muatan angkutan, maka salah satu dampak yang ditimbulkan terhadap prasarana jaringan jalan adalah tidak tercapainya umur rencana jalan sehingga biaya yang dikeluarkan untuk biaya konstruksi jalan yang ditimbulkan cukup besar, dampak lain yang ditimbulkan juga dampak keselamatan lalu lintas (kecelakaan) oleh karena itu penelitian mengenai tarif ini dirasa perlu dilakukan. Perhitungan tarif angkutan berdasarkan mengacu pada pedoman teknis penentuan tarif angkutan barang dan penumpang dari Dirjen Perhubungan Darat Kementerian Perhubungan dengan tiga komponen dasar yaitu biaya kepemilikan, Biaya Tetap dan Biaya Operasional Kendaraan (BOK).
\end{abstract}

Kata Kunci: Angkutan, Tarif, Operasional, BOK 


\begin{abstract}
ABSTRACK
Along with the increasing needs and economic development, the need for transportation of goods also increases with the logical consequences that will occur in the transportation of goods, namely the increase in value added prices of goods. Considering the financial value that will occur in the movement of goods transportation, the determination of freight rates is very dominant as the main factor that must be considered because tariff policies have a wide impact in the application of goods transportation. Tariff is the price level or cost paid by users of freight services per unit trip, weight or per unit volume per kilometer. Because the tariff is intended to encourage the optimum use of transportation infrastructure and facilities by considering the relevant traffic. In calculating the cost (freight rates) of goods using the approach. Vehicle production costs means that the freight rates are set based on vehicle operating costs plus a number of management percentages and benefits allowed. This case study reviews freight rates specifically for the Banjarmasin - Amuntai route along $\square 200 \mathrm{~km}$ by land transportation. Where in this case due to the low tariffs, the tendency of the owner of the transportation service to add to the amount of cargo transport, then one of the impacts on road network infrastructure is not achieving the life of the road plan so that the costs incurred for road construction costs incurred are quite large, other impacts also caused the impact of traffic safety (accidents), therefore research on this tariff is deemed necessary. The calculation of transportation tariffs is based on referring to the technical guidelines for determining freight and passenger transportation rates from the Director General of Land Transportation of the Ministry of Transportation with three basic components namely ownership costs, Fixed Costs and Vehicle Operating Costs (BOK)
\end{abstract}

Keywords: Transportation, Tariff, Operations, BOK.

\title{
PENDAHULUAN
}

Tarif adalah tingkat harga atau biaya yang dibayarkan oleh pengguna jasa angkutan barang persatuan trip, berat atau per satuan volume per kilometer. Penetapan tarif dimaksudkan untuk mendorong terciptanya penggunaan prasarana dan sarana perangkutan secara optimum dengan mempertimbangkan lintas yang bersangkutan.

Dalam perhitungan biaya (tarif angkutan) barang menggunakan pendekatan. Biaya produksi kendaraan artinya tarif angkutan barang tersebut ditetapkan berdasarkan biaya operasional kendaraan ditambah dengan sejumlah presentase pengelolaan dan keuntungan yang diperkenankan Studi kasus ini meninjau tarif angkutan barang khusus rute Banjarmasin - Amuntai sepanjang $\pm 198 \mathrm{~km}$ dengan angkutan darat. Dimana dalam kasus ini akibat tarif yang rendah menyebabkan kecenderungan pemilik jasa transportasi menambah jumlah muatan angkutan, maka salah satu dampak yang ditimbulkan terhadap prasarana jaringan jalan adalah tidak tercapainya umur rencana jalan sehingga biaya yang dikeluarkan untuk biaya konstruksi jalan yang ditimbulkan cukup besar, dampak lain yang ditimbulkan juga dampak keselamatan lalu lintas (kecelakaan) Oleh karena itu penelitian mengenai tarif ini dirasa perlu dilakukan. 


\section{Perumusan Masalah}

1. Berapakah tarif angkutan barang pada rute Banjarmasin - Amuntai Dihitung berdasarkan biaya kepemilikan atau biaya langsung dan biaya operasional kendaraan (BOK)?

2. Berapakah tarif angkutan barang berdasarkan perhitungan pemerintah melalui Organda?

\section{Tujuan Penelitian}

1. Untuk mengetahui nilai tarif angkutan barang pada rute Banjarmasin Amuntai Dihitung berdasarkan biaya kepemilikan atau biaya langsung dan biaya operasional kendaraan (BOK).

2. Untuk mengetahui dan membandingkan dengan tarif angkutan barang berdasarkan perhitungan pemerintah melalui Organda.

\section{Batasan Masalah}

1. Kendaraan yang diteliti adalah jenis kendaraan barang yang terbanyak melintas ruas Banjarmasin - Amuntai sepanjang $\pm 198 \mathrm{~km}$.

2. Komoditi yang diteliti adalah yang terbanyak diangkut oleh jenis kendaraan barang terbanyak melintas.

3. Penelitian ini hanya meninjau kasus tarif dan berat muatan yang diangkut dengan membandingkan tarif yang dianalisa berdasarkan biaya produksi.

4. Metode penentuan tarif menggunakan ketentuan dalam Keputusan Direktur Jenderal Perhubungan Darat Nomor 274/HK.105/DRJD/96 tentang pedoman Teknis Penyelenggaraan Angkutan Penumpang Umum di Wilayah Perkotaan Dalam Trayek Tetap dan Teratur, yang dimodifikasi sesuai dengan objek kendaraan barang.

\section{Metode Penentuan Tarif}

a. Biaya pokok atau biaya produksi adalah besaran pengorbanan yang dikeluarkan untuk menghasilkan satu satuan unit produksi jasa angkutan.

b. Tarif angkutan umum penumpang kota merupakan hasil perkalian antara tarif pokok dan jarak (Kilometer) rata-rata satu perjalanan (tarif BEP) dan ditambah $10 \%$ untuk jasa keuntungan perusahaan. Rumusannya adalah:

\begin{tabular}{|l|}
\hline Tarif $=($ tarif pokok $\mathrm{x}$ jarak rata-rata $)+10 \%$ \\
\hline Tarif $\mathrm{BEP}=$ tarif pokok $\mathrm{x}$ jarak rata-rata \\
\hline Tarif pokok $=\frac{\text { Total biaya pokok }}{\text { Faktor pengisian } \times \text { kapasitas kendaraan }}$ \\
\hline Km yang ditempuh per tahun $=\begin{array}{l}\text { Jarak trayek } \times \\
\text { Jumlah perjalanan dalam satu hari } \\
\text { Jumlah hari operasi satu bulan } \times \\
\text { Jumlah bulan dalam satu tahun }\end{array}$ \\
\hline
\end{tabular}

\section{METODOLOGI}




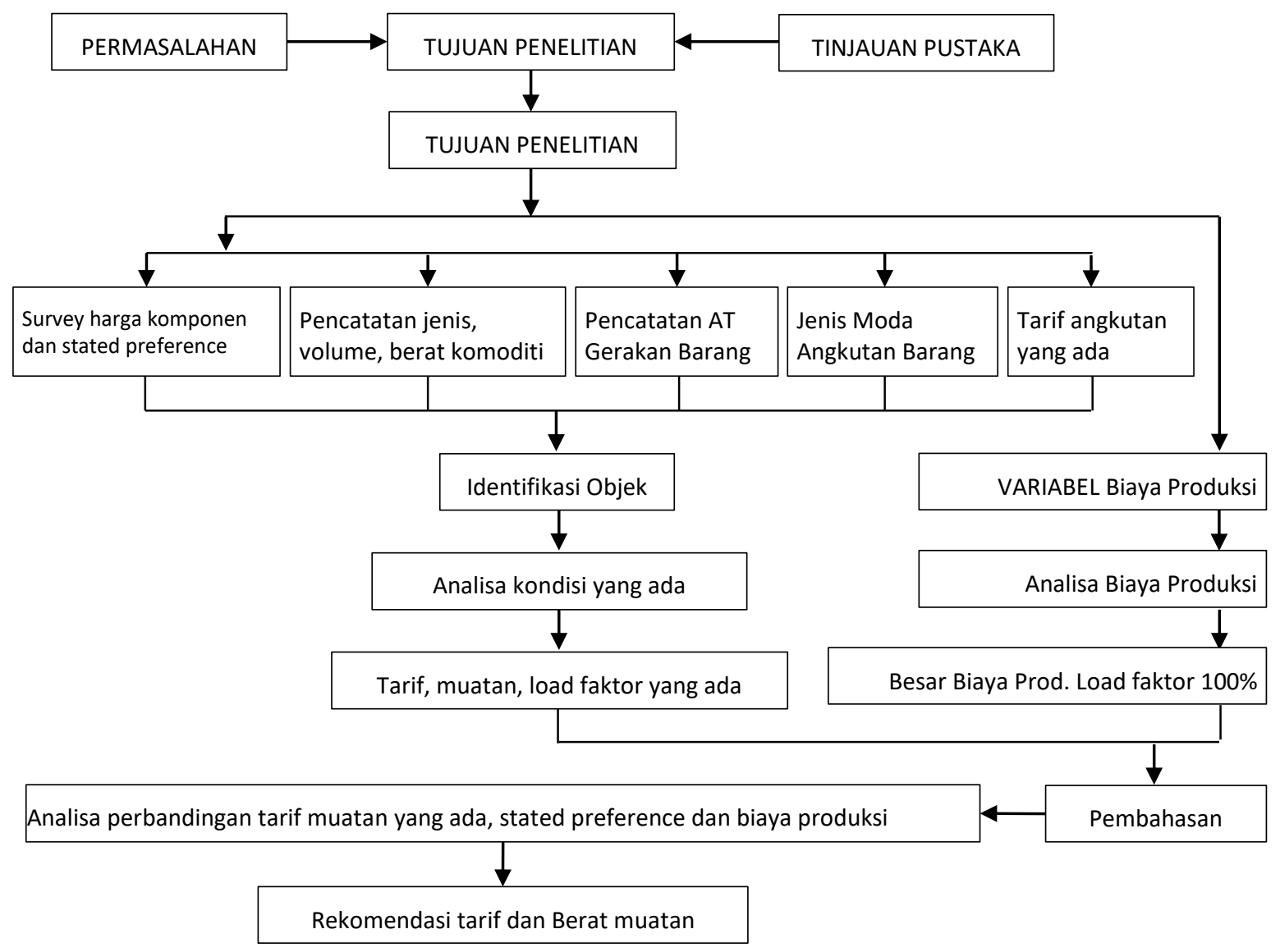

HASIL DAN PEMBAHASAN

Biaya penyusutan kendaraan produktif ini dihitung dengan menggunakan persamaan berikut:

Penyusutan per tahun $\quad=\frac{\text { Harga Kendaraan }- \text { Nilai Residu }}{\text { Masa Penyusutan }}$

Tabel 4.1 Depresiasi Truck dan Bus

\begin{tabular}{l|c|c|c|c|c|c|c|c|c|c|c|c}
\hline $\begin{array}{l}\text { Umur } \\
\text { Kendaraan }\end{array}$ & $<1$ & $1-2$ & $2-3$ & $3-4$ & $4-5$ & $5-6$ & $6-7$ & $7-8$ & $8-9$ & $9-10$ & $10-11$ & $>11$ \\
\hline $\begin{array}{l}\text { Depresiasi pada } \\
\text { masing-masing } \\
\begin{array}{l}\text { tahun } \\
(\%)\end{array}\end{array}$ & 19.8 & 17.2 & 12.1 & 9.6 & 8.1 & 7.1 & 6.3 & 5.8 & 5.3 & 4.9 & 2.8 & 0 \\
\hline
\end{tabular}




\section{Biaya Langsung (Biaya Tidak Tetap)}

1. Biaya bahan bakar minyak BBM/bus-km

$$
=\frac{\text { Pemakaian } B B M / b u s / h r}{K m \text { tempuh } / h r}
$$

2. Biaya ban /bus-km

$$
=\frac{\text { Jumlah pemakaian ban } \times \text { harga ban } / \text { buah }}{k m \text { daya tahan ban }}
$$

3. Biaya servis kecil/bus-km

$$
=\frac{\text { Biaya servis kecil }}{2000 \mathrm{~km}} \text {. }
$$

4. Biaya servis besar/bus-km

$$
=\frac{\text { Biaya sends besar }}{10000 \mathrm{~km}}
$$

5. Biaya overhoul/bus-km

$$
=\frac{\text { Biaya overhoul }}{200000 \mathrm{~km}}
$$

6. Biaya penambahan oli mesin/bus-km

$=\frac{\text { Penambahan oli } \times \text { harga oli } / \text { liter }}{k m-\text { tempuh }}$

7. Biaya suku cadang/bus-km

$$
=\frac{\text { Total biaya penggantian suku cadang }}{\mathrm{km} \text {-tempuh }}
$$

8. Biaya servis bodi /bus

$$
=\frac{\text { Total biaya servis bodi }}{\text { km tempuh }}
$$

9. Biaya cuci bus/bus-km

$$
=\frac{\text { Biaya cuci bus } / \text { bus }-\mathrm{km}}{\text { Produksi bus }-\mathrm{km} / \text { bulan }} \text {. }
$$

\section{Biaya Tidak Langsung (Biaya Tetap)}

Biaya tidak langsung (Biaya tetap) pada angkutan umum antara lain terdiri dari:

- Biaya pegawai selain awak kendaraan

- Gaji/upah

- Tunjangan sosial seperti: lebaran, natal, dan tahun baru

- Uang lembur

\section{Biaya Kepemilikan Usaha Kendaraan dan Operasi}

Biaya kepemilikan usaha kendaraan dan operasi kendaraan sebagai berikut:

- Surat Tanda Nomor Kendaraan (STNK)

- Retrebusi diterminal Bea Balik Nama (BBN)

- Pemeriksaan kendaraan (kir)

- Calo diterminal.

\section{Produksi Pelayanan Angkutan Umum}

Produksi pelayanan angkutan umum menurut keputusan Direktorat Jendral Perhubungan Darat No. 274/HK.105/DRJD/96. Parameter produksi pelayanan angkutan umum mempunyai tiga alternatif besaran yang dapat ditinjau yaitu: 


\section{Jumlah Load-trip Persatuan Waktu}

Seat/trip adalah besaran yang menunjukan jumlah tempat duduk trip yang tersedia dari suatu pelayanan angkutan umum persatuan waktu. Besaran ini pada dasarnya hanya menunjukan kapasitas angkutan yang dapat diberikan oleh suatu sistem angkutan umum persatuan waktu. sebanyak (N) kali .Besarnya produksi pelayanan angkutan umum per tahunnya dengan besarnya seabtrip sebagai berikut: Total seat-trip = kapasitas angkut $\times$ jumlah trip per tahun $=(\mathrm{M} \times \mathrm{N})$ Perhitungan total seat-trip memerlukan kapasitas kendaraan dan jumlah trip yang dapat dilakukan per satuan waktu.

\section{Jumlah Barang - Kilometer per Satuan Waktu}

Jumlah penumpang-kilometer per satuan waktu adalah besaran yang menunjukkan karakteristik barang yang terangkut dari suatu pelayanan umum. Karakteristik dimaksud meliputi karakteristik panjang perjalanan dan juga karakteristik jumlah barang dengan sendirinya, karena tiap rute mempunyai karaktenstik panjang perjalanan yang berbeda maka besaran produksi perjalanan angkutan umum dengan dimensi ini sangat berpariasi untuk setiap rutenya tergantung jumlah dan panjang perjalanan barang. Untuk menghitung besaran total produksi pelayanan angkutan umum dengan menggunakan dimensi barang kilometer ini perlu dibuat profil pengisian (loading profile) angkutan dalam satu trip, profil pengisian ini merupakan grafik yang akan menggambarkan besar kecilnya penumpang di dalam kendaraan pada setiap perhentian untuk satu trip.

\section{Biaya Pokok Produksi Menurut Operator}

Biaya pokok produksi menurut operator didefinisikan sebagai biaya yang didapat dari perhitungan jumlah biaya produksi layanan angkutan barang dibagi dengan jumlah produksi layanan angkutan.

Biaya tersebut didapat dengan menggunakan persamaan berikut:

Biaya pokok produksi $(\mathrm{Rp} / \mathrm{Km})$

$$
=\frac{\text { Biaya produksi layanan }(R p)}{\text { Produksi layanan angkutan }(\mathrm{Km})}
$$

Perhitungan Biaya Pokok Produksi pada penelitian ini menggunakan metode Pasific Consultant International (PCI) yang telah direvisi (1990). Sebagai koreksi terhadap Biaya pokok produksi yang dihitung menurut metode operator. Model ini termuat dalam Feasibility Study Jakarta intra Urban dan Feasibility Study on The Cikampek-Cirebon Tollway Project, 1990.

\section{Biaya Pokok Produksi Metode PCI}

Biaya pokok produksi berdasarkan metode PCI (Pasific Consultants Internasional) Kensuke (1990), adalah sebagai berikut:

\section{Biaya Operasi Mobil Penumpang (Passanger Car)}


1. Konsumsi Bahan Bakar $Y=\left(0,03719 S^{2}-4.19966 S+175.9911\right) \times$ harga bensin per liter

Dimana : $\mathrm{Y}=$ konsumsi bahan bakar (liter/1000 km)

$$
\mathrm{S}=\text { running speed }(\mathrm{km} / \mathrm{jam})
$$

2. Konsumsi Oli Mesin

$\mathrm{Y}=\left(0.00025 \mathrm{~S}^{2}-0.02664 \mathrm{~S}+1.44170\right) \times$ harga oli per liter

Dimana: $\mathrm{Y}=$ konsumsi minyak pelunas $($ liter $/ 1000 \mathrm{~km})$

$\mathrm{S}=$ running speed $(\mathrm{km} / \mathrm{jam})$

3. Pemakaian Ban

$\mathrm{Y}=(0.0008848 \mathrm{~S}+0.0045333) \times$ harga ban per buah

Dimana: $\mathrm{Y}=$ konsumsi ban $(1 \mathrm{ban} / 1000$ kendaraan $)$

$\mathrm{S}=$ running speed $(\mathrm{km} / \mathrm{jam})$

4. Biaya Pemeliharaan Onderdil

$\mathrm{Y}=(0.0000064 \mathrm{~S}+0.0005567) \times$ harga mobil

Dimana: $\mathrm{Y}=$ total perbaikan dan pemeliharaan dihitung dari nilai penyusutan kendaraan per $1000 \mathrm{~km}$.

$\mathrm{S}=$ running speed $(\mathrm{km} / \mathrm{jam})$

5. Biaya Mekanik

$\mathrm{Y}=(0.00362 \mathrm{~S}+036267) \times$ ongkos per jam

Dimana : $Y=$ jumlah jam-jam kerja per $1000 \mathrm{~km}$

$\mathrm{S}=$ running speed $(\mathrm{km} / \mathrm{jam})$.

6. Penyusutan Kendaraan/Depresiasi

$\mathrm{Y}=(2.5 \mathrm{~S}+125)$ "' $\times$ harga mobil

Dimana: $\mathrm{Y}=$ penyusutan kendaraan per $1000 \mathrm{~km}$ dikalikan dengan nilai susut kendaraan.

$\mathrm{S}=$ running speed $(\mathrm{km} / \mathrm{jam})$

7. Suku Bunga

$\mathrm{Y}=(0.12 \backslash 1000) \times /(500 \mathrm{~S})) \times$ harga mobil

Dimana: $\mathrm{Y}=$ suku bunga per $1000 \mathrm{~km}$

$\mathrm{S}=$ running speed $(\mathrm{km} / \mathrm{jam})$

8. Asuransi

$\mathrm{Y}=(0,035 \times 1000 \times 0,5) /(500 \mathrm{~S})) \times$ harga mobil

dimana: $\mathrm{Y}=$ asuransi per $1000 \mathrm{~km}$

$\mathrm{S}=$ running speed $(\mathrm{km} / \mathrm{jam})$

9. Upah Crew

$\mathrm{Y}=(1000 / \mathrm{S}) \times($ upah sopir + upah kondektur $)$

Dimana : $\mathrm{Y}=$ upah sopir + upah kondektur per $1000 \mathrm{~km}$

$\mathrm{S}=$ running speed $(\mathrm{km} / \mathrm{jam})$

10. Biaya Overhead

$10 \%$ dari jumlah sub total biaya (a) sampai dengan (i) di atas.

\section{Biaya Operasi Angkutan Umum (Micro Bus)}


1. Konsumsi Bahan Bakar $Y=\left(0,03719 S^{2}-4.19966 S+175.9911\right) \times$ harga bensin per liter

Dimana : $\mathrm{Y}=$ konsumsi bahan bakar (liter/1000 km)

$$
\mathrm{S}=\text { running speed }(\mathrm{km} / \mathrm{jam})
$$

2. Konsumsi Oli Mesin

$\mathrm{Y}=\left(0.00025 \mathrm{~S}^{2}-0.02664 \mathrm{~S}+1.44170\right) \times$ harga oli per liter

Dimana: $\mathrm{Y}=$ konsumsi minyak pelunas (liter/1000km)

$\mathrm{S}=$ running speed $(\mathrm{km} / \mathrm{jam})$

3. Pemakaian Ban

$\mathrm{Y}=(0.0008848 \mathrm{~S}+0.0045333) \times$ harga ban per buah

Dimana: $\mathrm{Y}=$ konsumsi ban $(1 \mathrm{ban} / 1000$ kendaraan $)$

$\mathrm{S}=$ running speed $(\mathrm{km} / \mathrm{jam})$

4. Biaya Pemeliharaan Onderdil

$\mathrm{Y}=(0.0000064 \mathrm{~S}+0.0005567) \times$ harga mobil

Dimana: $\mathrm{Y}=$ total perbaikan dan pemeliharaan dihitung dari nilai penyusutan kendaraan per $1000 \mathrm{~km}$

$\mathrm{S}=$ running speed $(\mathrm{km} / \mathrm{jam})$

5. Biaya Mekanik

$\mathrm{Y}=(0.00362 \mathrm{~S}+036267) \times$ ongkos per jam

Dimana : $Y=$ jumlah jam-jam kerja per $1000 \mathrm{~km}$

$\mathrm{S}=$ running speed $(\mathrm{km} / \mathrm{jam})$

6. Penyusunan Kendaraan/Depresiasi

$\mathrm{Y}=(2,5 \mathrm{~S}+125)^{-1} \times$ harga mobil

Dimana: $\mathrm{Y}=$ penyusutan kendaraan per $1000 \mathrm{~km}$ dikalikan dengan nilai susut kendaraan.

$\mathrm{S}=$ running speed $(\mathrm{km} / \mathrm{jam})$

7. Suku Bunga

$\mathrm{Y}=(0.12 \times 1000) \times /(500 \mathrm{~S})) \times$ harga mobil

Dimana : $\mathrm{Y}=$ suku bunga per $1000 \mathrm{~km}$

$\mathrm{S}=$ running speed $(\mathrm{km} / \mathrm{jam})$

8. Asuransi

$\mathrm{Y}=((0,035 \times 1000 \times 0,5) /(500 \mathrm{~S})) \times$ harga mobil

Dimana: $\mathrm{Y}=$ asuransi per $1000 \mathrm{~km}$

$\mathrm{S}=$ running speed $(\mathrm{km} / \mathrm{jam})$

9. Upah Crew

$\mathrm{Y}=(1000 / \mathrm{S}) \times($ upah sopir + upah kondektur $)$

Dimana : $\mathrm{Y}=$ upah sopir + upah kondektur per $1000 \mathrm{~km}$

$\mathrm{S}=$ running speed $(\mathrm{km} / \mathrm{jam})$

10. Biaya Over Head

$10 \%$ dari jumlah sub total biaya (a) sampai dengan (i) di atas.

\section{Biaya Operasi Bus Sedang (Medium Bus)}


Persamaan yang digunakan untuk menghitung biaya pokok produksi Bus pada penelitian ini menurut Kensuke (1990):

1. Konsumsi Bahan Bakar $\mathrm{Y}=\left(0,06846 \mathrm{~S}^{2}-8.02987 \mathrm{~S}+340.6040\right) \times$ harga solar per liter

Dimana : $\mathrm{Y}=$ konsumsi bahan bakar (liter/1000 km)

$\mathrm{S}=$ running speed $(\mathrm{km} / \mathrm{jam})$

2. Konsumsi Oli Mesin

$\mathrm{Y}=\left(0.00057 \mathrm{~S}^{2}-0.06130 \mathrm{~S}+3.37530\right) \times$ harga oli per liter

Dimana: $\mathrm{Y}=$ konsumsi minyak pelunas $($ liter $/ 1000 \mathrm{~km})$

$\mathrm{S}=$ running speed $(\mathrm{km} / \mathrm{jam})$

3. Pemakaian Ban

$\mathrm{Y}=(0.0012356 \mathrm{~S}+0.0064667) \times 6 \times$ harga ban per buah

Dimana: $\mathrm{Y}=$ konsumsi ban $(1 \mathrm{ban} / 1000$ kendaraan $)$

$\mathrm{S}=$ running speed $(\mathrm{km} / \mathrm{jam})$

4. Biaya Pemeliharaan Onderdil

$\mathrm{Y}=(0.0000332 \mathrm{~S}+0.0020891) \times$ harga bus

Dimana: $\mathrm{Y}=$ total perbaikan dan pemeliharaan dihitung dari nilai penyusutan kendaraan per $1000 \mathrm{~km}$

$\mathrm{S}=$ running speed $(\mathrm{km} / \mathrm{jam})$

5. Biaya Mekanik

$\mathrm{Y}=(0.02311 \mathrm{~S}+1.97733) \times$ ongkos per jam

Dimana: $Y=$ jumlah jam-jam kerja per $1000 \mathrm{~km}$

$\mathrm{S}=$ running speed $(\mathrm{km} / \mathrm{jam})$

6. Penyusunan Kendaraan/Depresiasi

$\mathrm{Y}=(8.756 \mathrm{~S}+350)^{-1} \times$ harga mobil

Dimana: $\mathrm{Y}=$ penyusutan kendaraan per $1000 \mathrm{~km}$ dikalikan dengan nilai susut kendaraan.

$\mathrm{S}=$ running speed $(\mathrm{km} / \mathrm{jam})$

7. Suku Bunga

$\mathrm{Y}=(0,12 \times 1000) \times /(2500 \mathrm{~S})) \times$ harga mobil

Dimana : $\mathrm{Y}=$ suku bunga per $1000 \mathrm{~km}$

$\mathrm{S}=$ running speed $(\mathrm{km} / \mathrm{jam})$

8. Asuransi

$\mathrm{Y}=((0,04 \times 1000 \times 0,5) /(2500 \mathrm{~S})) \times$ harga mobil

Dimana : $\mathrm{Y}=$ asuransi per $1000 \mathrm{~km}$

$\mathrm{S}=$ running speed $(\mathrm{km} / \mathrm{jam})$

9. Upah Crew

$\mathrm{Y}=(1000 / \mathrm{S}) \times($ upah sopir + upah kondektur $)$

Dimana : $\mathrm{Y}=$ upah sopir + upah kondektur per $1000 \mathrm{~km}$

$\mathrm{S}=$ running speed $(\mathrm{km} / \mathrm{jam})$

10. Biaya Over Head

$10 \%$ dari jumlah sub total biaya (a) sampai dengan (i) di atas.

\section{Biaya Operasi Bus Sedang (Standar Bus)}


1. Konsumsi Bahan Bakar

$Y=\left(0,12292 S^{2}-13.68742 S+541.0279\right) \times$ harga solar per liter

Dimana: $\mathrm{Y}=$ konsumsi bahan bakar (liter/1000km)

$\mathrm{S}=$ running speed $(\mathrm{km} / \mathrm{jam})$

2. Konsumsi Oli Mesin

$\mathrm{Y}=\left(0.00130 \mathrm{~S}^{2}-0.12968 \mathrm{~S}+7.06239\right) \times$ harga oli per liter

Dimana: $\mathrm{Y}=$ konsumsi minyak pelunas $($ liter $/ 1000 \mathrm{~km})$

$\mathrm{S}=$ running speed $(\mathrm{km} / \mathrm{jam})$

3. Pemakaian Ban

$Y=(0.0012356 S+0.0064667) \times 6 \times$ harga ban per buah

Dimana: $\mathrm{Y}=$ konsumsi ban $(1 \mathrm{ban} / 1000$ kendaraan $)$

$\mathrm{S}=$ running speed $(\mathrm{km} / \mathrm{jam})$

4. Biaya Pemeliharaan Onderdil

$\mathrm{Y}=(0.0000332 \mathrm{~S}+0.0020891) \times$ harga mobil

Dimana: $\mathrm{Y}=$ total perbaikan dan pemeliharaan dihitung dari nilai penyusutan kendaraan per $1000 \mathrm{~km}$

$\mathrm{S}=$ running speed $(\mathrm{km} / \mathrm{jam})$

5. Biaya Mekanik

$\mathrm{Y}=(0.02311 \mathrm{~S}+1.97733) \times$ ongkos per jam

Dimana: $Y=$ jumlah jam-jam kerja per $1000 \mathrm{~km}$

$\mathrm{S}=$ running speed $(\mathrm{km} / \mathrm{jam})$

6. Penyusunan Kendaraan/Depresiasi

$\mathrm{Y}=(8,756 \mathrm{~S}+350)^{-1} \times$ harga mobil

Dimana: $\mathrm{Y}=$ penyusutan kendaraan per $1000 \mathrm{~km}$ dikalikan dengan nilai susut kendaraan

$\mathrm{S}=$ running speed $(\mathrm{km} / \mathrm{jam})$

7. Suku Bunga

$Y=(0,12 \times 1000) \times /(2500 \mathrm{~S})) \times$ harga mobil

Dimana: $\mathrm{Y}=$ suku bunga per $1000 \mathrm{~km}$

$\mathrm{S}=$ running speed $(\mathrm{km} / \mathrm{jam})$

8. Asuransi

$\mathrm{Y}=((0,04 \times 1000 \times 0,5) /(2500 \mathrm{~S})) \times$ harga mobil

Dimana: $\mathrm{Y}=$ asuransi per $1000 \mathrm{~km}$

$\mathrm{S}=$ running speed $(\mathrm{km} / \mathrm{jam})$

9. Upah Crew

$\mathrm{Y}=(1000 / \mathrm{S}) \times($ upah sopir + upah kondektur $)$

Dimana : $\mathrm{Y}=$ upah sopir + upah kondektur per $1000 \mathrm{~km}$

$\mathrm{S}=$ running speed $(\mathrm{km} / \mathrm{jam})$

10. Biaya Over Head

$10 \%$ dari jumlah sub total biaya (a) sampai dengan (i) di atas.

\section{Kesimpulan}


Dari uraian diatas didapatkan tarif angkutan barang dalam satuan berat $(\mathrm{kg})$ senilai dari Kota Banjarmasin - Kota Amuntai sebesar Rp.6.000,- sedangkan dengan satuan volume $\left(\mathrm{m}^{3}\right)$ dari Kota Banjarmasin - Kota Amuntai sebesar Rp.125.000,begitu juga nilai tersebut diatas berlaku pada route sebaliknya yaitu Amuntai Banjarmasin, tarif ini lebih tinggi dibandingkan dengan yang ditetapkan oleh pemerintah melalui Organda yaitu tarif angkutan barang dalam satuan berat $(\mathrm{kg})$ senilai dari Kota Banjarmasin - Kota Amuntai sebesar Rp.5.500,- sedangkan dengan satuan volume $\left(\mathrm{m}^{3}\right)$ dari Kota Banjarmasin - Kota Amuntai sebesar Rp.115.000,-.

\section{DAFTAR PUSTAKA}

Abubakar, Iskandar dkk (1997) Menuju Lalu Lintas dan Angkutan Jalan Yang Tertib. Direktorat Jenderal Perhubungan Darat, Jakarta.

Abuhakar, Iskandar dkk (1999) Pedoman Perencanaan dan Pengoperasian Lalu Lintas di Wilayah Perkotaan, Direktorat Jenderal Perhubungan Darat, Jakarta.

Keputusan Direktur Jenderal Perhubungan Darat Nomor 274/HK.105/DRJD/96 tentang Pedoman Teknis Penyelenggaraan Angkutan Penumpang Umum di Wilayah Perkotaan Dalam Trayek Tetap dan Teratur.

Peraturan Pemerintah Nomor 41Tahun 1993 tentang Angkutan Jalan.

Peraturan Pemerintah Nomor 43 Tahun 1993 tentang Lalu Lintas dan Prasarana Jalan.

Peraturan Pemerintah Nomor 44 Tahun 1993 tentang Kendaraan dan Pengemudi.

Tamm, O.Z (2000) Perencanaan dan Permodelan Transportasi; Edisi Pertama Penerbit ITB, Bandung.

Undang-undang Nomor 14 Tahun 1992 tentang Lalu Lintas dan Angkutan Jalan. 